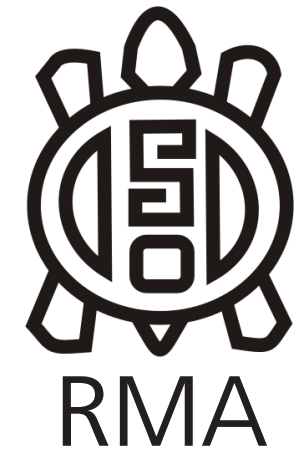

Arqueología

\title{
Un barreal con 2000 años de historia: La Troya, departamento Tinogasta, Catamarca
}

\author{
A muddy place with 2000 years of history: La Troya, Tinogasta \\ Department, Catamarca
}

Norma Ratto* y Anabel Feely**

*Universidad de Buenos Aires, Instituto de las Culturas (UBA-CONICET), Facultad de Filosofía y Letras. E-mail: nratto@filo.uba.ar

** Instituto de las Culturas (UBA-CONICET), Facultad de Filosofía y Letras.

E-mail: anabel.feely@gmail.com

\begin{abstract}
Resumen
En este trabajo integramos espacial y temporalmente la información primaria y secundaria del barreal de La Troya (departamento Tinogasta, Catamarca), la cual fue generada por distintos actores y circunstancias en el desarrollo de la práctica arqueológica, específicamente los pioneros de la disciplina, las colecciones en guarda en museos, los estudios de impacto y los proyectos de investigación. Damos cuenta de la historia socioambiental del barreal a lo largo de casi 2000 años y la contextualizamos con las características del proceso a escala regional. Los resultados definen al barreal como un espacio persistente donde distintas organizaciones sociales, económicas y políticas se asentaron construyendo sus poblados, realizando actividades productivas y enterrando a sus muertos desde las sociedades del primer milenio hasta momentos hispano-indígenas.
\end{abstract}

Palabras clave: Barreal de La Troya; Historia socioambiental; Espacio persistente; Oeste de Tinogasta.

\begin{abstract}
This work integrates, spatially and temporally, the primary and secondary information of the barreal of La Troya (Tinogasta, Catamarca), generated in different circumstances during the development of the archaeological practice: the work of the pioneers of the discipline, museum collections, impact studies and research projects. We present the socio-environmental history over almost 2000 years and contextualize it with the characteristics of the process on a regional scale. The results define the barreal as a persistent space where different social, economic and political organizations settled, building their villages, carrying out productive activities and burying their dead since the societies of the first millennium until Spanish-indigenous moments.
\end{abstract}

Keywords: Barreal of La Troya; Socio-environmental history; Persistent space; West Tinogasta.

\section{Introducción}

El amplio abanico aluvial de río La Troya ocupa aproximadamente $43 \mathrm{~km}^{2}$, y se desarrolla desde la boca de la quebrada homónima hasta su desagüe en el río Abaucán (Figura 1). Este espacio fue bisecado por la construcción de la RN60 en la década de 1960, en cuyo lateral Oeste se extiende un tendido eléctrico, y cuenta con el desarrollo de emprendimientos agrícolas de olivos con riego por goteo. A las obras productivas y de infraestructura debe sumársele la realización de intensas intervenciones arqueológicas a partir del siglo XIX, tanto asistemáticas como sistemáticas, como así también la acción de agentes naturales, especialmente el agua (Raffino 1993-1998; Ratto et al. 2013 a). A lo largo de estas páginas presentamos la historia socioambiental del barreal de La Troya, habitado desde el siglo IV al XVIII de la era, y la contextualizamos a escala regional con el intricado proceso sociocultural del oeste de Tinogasta (Catamarca). Sostenemos que su ocupación intensiva y continua en el tiempo lo definen como un «espacio persistente» (sensu Schlanger 1992) donde se desarrollaron distintos contextos sociohistóricos a lo largo de ese extenso lapso.

A pesar de la abundante producción científica generada específicamente en torno al barreal de La Troya, o su relación con otras áreas de la región de Fiambalá, no se cuenta con un análisis integrador que dé cuenta del intenso uso de este espacio por distintos contextos sociohistóricos a lo largo del tiempo, los cuales fueron alterados por agentes naturales y culturales, 


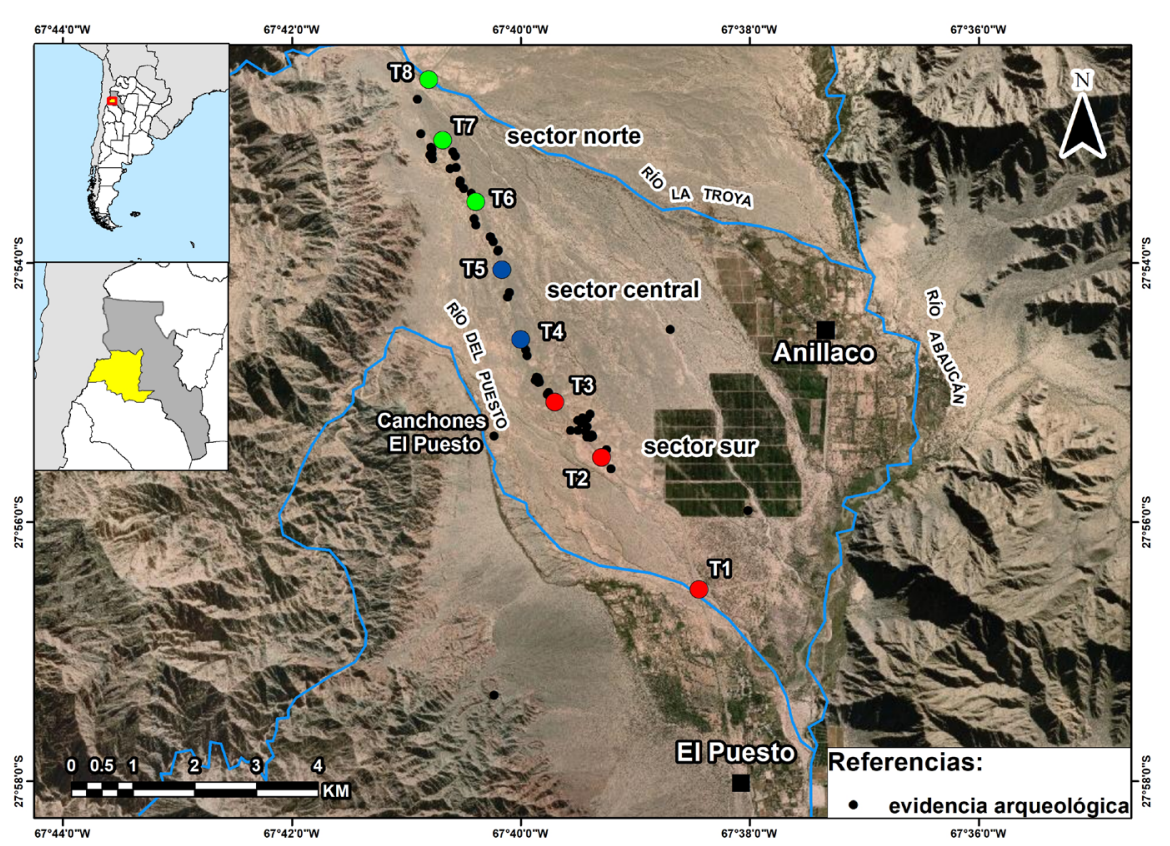

Figura 1. Barreal de La Troya, departamento de Tinogasta, Catamarca. Demarcación de sectores en tramos $(T)$ de $1 \mathrm{~km}$ lineal de extensión cada uno

Figure 1. Barreal of $L a$ Troya, Tinogasta, Catamarca. Demarcation of sector in sections (T) of 1 linear $\mathrm{km}$ in length each

milenio; y (iii) de producción alfarera, representados por estructuras de combustión (hornos) de formas circulares y de ojo de cerradura, que también remiten a ambos milenios. Por último, en la tercera sección integramos y discutimos los resultados

principalmente por las asiduas crecientes del río La Troya y las intensas acciones vandálicas que sufrió el área (ver más adelante). Consideramos que integrar espacial y temporalmente toda la información generada por distintos actores conforma la clave para comprender y discutir las similitudes y/o diferencias en el uso de este espacio a lo largo del tiempo. Es por ello que nos parece importante articular tanto la información primaria como la secundaria existente. La primera es la generada por nuestro proyecto de investigación y los estudios de impacto realizados por sus integrantes; mientras que la secundaria proviene de diversas fuentes generadas por los pioneros que trabajaron en el área y/o los formadores de colecciones públicas y privadas.

Por lo expuesto, organizamos esta presentación en diferentes secciones que serán integradas en la discusión. La primera hace referencia a los antecedentes del área del barreal, incluidos los procesos de formación naturales y culturales, los antecedentes arqueológicos de las intervenciones que se realizaron, y los lineamientos metodológicos que sustentan nuestra lectura de los procesos socioambientales acaecidos. La segunda refiere a la materialidad cultural del barreal de La Troya recuperada a través de la implementación de una metodología distribucional en la realización de estudios de impacto, cuyos resultados se integraron al proyecto de investigación arqueológico Chaschuil-Abaucán. Esto permitió identificar densidades y composiciones diferenciales del registro arqueológico que presenta distribución continua a lo largo de los $8 \mathrm{~km}$ de extensión del barreal. De esta manera se identificaron e intervinieron sitios arqueológicos de diversas funciones, articulando los trabajos de impacto con los de investigación: (i) residenciales, como la aldea LTV50 del primer milenio de la era y la instalación estatal de Batungasta; (ii) funerarios, tanto directos en tierra como en urna, los que también remiten al primero y segundo obtenidos para dar cuenta de los cambios y continuidades en el uso de este espacio a lo largo del tiempo.

Nuestra hipótesis de trabajo es que el barreal de La Troya se presenta como un espacio persistente a lo largo del tiempo (sensu Schlanger 1992), un espacio habitado y reiteradamente modificado desde las primeras sociedades aldeanas hasta momentos hispano-indígenas, donde cada comunidad que se asentó, con organizaciones sociales, económicas y políticas diversas, impuso su impronta en la construcción de sus poblados, la realización de actividades de producción alfarera y agrícola, y en la forma de enterrar a sus muertos. Aclaramos que concebimos al espacio en su dimensión tridimensional donde articulan los entornos físico, sociocultural y simbólico-ideológico, no como escenario físico pasivo y estático, sino como una entidad activa que estructura las prácticas sociales (Criado Boado 1993; David y Thomas 2008).

\section{Antecedentes arqueológicos del barreal de La Troya}

El sudoeste del departamento de Tinogasta de la provincia de Catamarca no tuvo un papel relevante en la construcción de la arqueología del NOA ya que se caracterizó por registrar tímidos acercamientos y largos silencios, los que se revierten recién a mediados de la década del 2000. Esto se debe, en gran parte, a que no contó con las largas expediciones que los pioneros realizaron en los valles orientales de Belén y Santa María en los siglos XIX y comienzo del XX; conociéndose solo cortas excursiones que se restringieron al sector Norte del barreal de La Troya, principalmente el sitio Batungasta, Watungasta o Huatungasta y áreas adyacentes, reportadas en publicaciones (Lafone Quevedo 1892; Lange 1892), libretas de campo (Uhle 1893; Weiser 1921-1926) y fichas de registro del Depósito 25 del Museo de La Plata (Colección Moreno y Lafone Quevedo). 
Luego, en la década de 1950, incursionó por el sitio el jesuita Oscar Dreidemie, según consta en las fichas depositadas en el Museo Jesuítico Nacional de Jesús María (MJNJM), Córdoba. Recién en la década de 1960, González y Sempé (1975) efectuaron un relevamiento sistemático, describieron el material recolectado y adscribieron la instalación como incaica con posterior ocupación española, particularmente las construcciones de adobe. Luego, los trabajos continuaron por Raffino y colaboradores (1984) en la década de 1980. Cada una de estas intervenciones realizaron recolecciones de materiales en superficie y muy posiblemente en excavaciones, de los cuales, en su mayoría, se desconoce el paradero, con excepción de los que están depositados en los museos nacionales (Jesús María y La Plata), con registro de fichas de catálogo muy generales, y del extranjero (Etnológico de Berlín, Colección Uhle) que cuenta tanto con libretas, inventarios y fichas de catálogo (Ratto 2015).

A los trabajos de los pioneros y primeros investigadores hay que sumarle las recolecciones y excavaciones realizadas por pobladores locales, especialmente en los campos de La Troya, que es el nombre que ellos le dan. Este accionar dio como resultado la conformación de grandes colecciones depositadas en el Museo Municipal Robaudi y en el Museo Privado Alanis, ambos localizados en la ciudad de Tinogasta (STN 1998). Estas no cuentan con respaldo de fichas de catálogo, ni libretas de campo, y la proveniencia de los materiales ha sido inferida a través de la historia oral de pobladores que intervinieron en los trabajos, principalmente en el caso de la familia Robaudi. Pero los procesos de formación de sitio de carácter cultural en el área del sitio Batungasta se agudizan todos los años para Semana Santa y la Fiesta de la Pachamama, cuando los pobladores locales realizan excavaciones para buscar el "gallito de oro" y ceremonias conmemorativas, respectivamente.

Aunque las intervenciones arqueológicas recorrieron un largo camino, éstas no se desarrollaron de igual manera a lo largo de toda la extensión del amplio barreal de La Troya, por lo que la profundidad temporal de la ocupación del área fue subestimada. Los trabajos de los pioneros, clérigo e investigadores tuvieron su epicentro en el sector Norte del barreal, específicamente donde se localiza el sitio Batungasta y su periferia inmediata, por lo que la comprensión de este espacio se acotó solo a tiempos incaicos e hispano-indígena (Caletti 2005; De La Fuente 2007; Feely 2003; González y Sempé 1975; Lafone Quevedo 1892; Lange 1892; Orgaz y Ratto 2015, 2016; Raffino 1995; Raffino et al. 1983-1985; Ratto et al. 2002; Sempé 1977; libretas de campo de Uhle en Ratto 2015; entre otros). Es recién con la realización de los estudios de impacto que se amplió el espacio investigado y con ello se descubrió la mayor profundidad temporal del barreal, que lo retrotrae al siglo IV de la era, momento de desarrollo de las primeras sociedades agroalfareras (Ratto 2005 a, b, c y d). Estos resultados, de cuenta larga, se articularon e integraron con distintas líneas de investigación del PACh-A para analizar el devenir socioambiental de la región de Fiambalá, de la que el barreal de La Troya forma parte, a lo largo de los últimos 2000 años. Consideramos que toda práctica se produce y reproduce en permanente articulación con otras y con las condiciones del medio físico en que se desarrollan. Así, los estudios estuvieron dirigidos al análisis de contextos residenciales, funerarios, productivos alfareros, agrícolas y de minería no-metalífera, tanto en sus dimensiones materiales como simbólicas (Andreoni et al. 2018; Feely 2011, 2012; Feely y Ratto 2009; Orgaz et al. 2014; Orgaz y Ratto 2013, 2015, 2020; Ratto et al. 2007; entre otros); como así también a la realización de estudios paleoambientales (Ratto et al. 2013a, Fernández-Turiel 2019), la aplicación de métodos y técnicas geofísicas (Ratto et al. 2013b) y el análisis de fuentes etnohistóricas (Ratto y Boixadós 2012). Al respecto, y a modo de resumen regional, la inestabilidad ambiental, la ausencia de fechados radiométricos en el fondo del valle entre los años 1000 a 1200 de la era, la continuidad de las prácticas de las poblaciones del primer milenio hasta el siglo XIII, la ausencia de un Período Tardío -o de Desarrollo Regional o Intermedio Tardío-, característico en los valles del oriente, y la reocupación por parte del inca de espacios con historia previa de momentos de las sociedades del primer milenio; todo en su conjunto, está indicando que el proceso cultural no fue lineal ni mecánico, marcado por una dinámica de poblamiento, despoblamiento, repoblamiento -inca y poblaciones movilizadas-, y nuevo despoblamiento -conquista española y la conformación de las encomiendas- (Ratto y Boixadós 2012, Ratto 2013).

En resumen, el Proyecto Arqueológico Chaschuil-Abaucán inició sus trabajos en el área de La Troya en el año 1996, el sitio Batungasta ya había sido sometido a profundas alteraciones, tanto por los agentes naturales como humanos. Por eso los trabajos se extendieron a la periferia Norte y Sur, y posteriormente fueron ampliados a través de la realización de estudios de impacto arqueológico dentro del área principal del barreal, desde el río El Puesto hasta el río La Troya, cubriendo un área de $8000 \mathrm{~m}$ de largo, en sentido del desplazamiento de la RN60, por 200 $\mathrm{m}$ de ancho, equivalente a $1.600 .000 \mathrm{~m}^{2}$ (Ratto 2005 a), y en sectores internos del barreal, hacia el Este, cubriendo una superficie de $770.000 \mathrm{~m}^{2}$ (Ratto 2005 c y d). Toda esta información (antecedentes publicados, libretas de campo, colecciones en museo, estudios de impacto y proyectos de investigación) son la base que permite delinear la historia socioambiental del barreal de La Troya.

\section{Características socioambientales del barreal de La Troya y sus antecedentes de investigación}

\section{Lineamientos metodológicos}

Tanto al inicio de las investigaciones del PACh-A en el 
área Norte del barreal de La Troya, principalmente en el sitio Batungasta y áreas adyacentes (De La Fuente 2007; Feely 2003; Ratto et al. 2002), como durante la ejecución de los estudios de impacto arqueológico por la repavimentación de la RN60 (Ratto 2005 a, b) y emprendimientos agrícolas (Ratto 2005 c, d), se desarrolló una metodología distribucional para conocer el perfil arqueológico del barreal, se documentaron las características del relieve y las alteraciones y/o rasgos del ambiente físico (huellas vehiculares y de maquinarias, sendas, basurales, movimientos de suelo, alteraciones vandálicas, cárcavas y médanos), y se procedió al registro y recuperación del material arqueológico existente dentro de cada unidad de muestreo (para una descripción de la metodología utilizada ver Ratto 2005 a, b, c y d). Aquellas altas concentraciones de materiales, artefactos, ecofactos y/o estructuras, que daban cuenta de una organización planificada del espacio con distintas funciones (residenciales, funerarios y productivos alfareros), fueron sujetas a intervenciones por excavación. Aclaramos que compartimos los alcances metodológicos de la arqueología distribucional para el análisis de los materiales en superficie.

La metodología distribucional permitió generar una información de base conformada por datos primarios que a su vez articularon con los aportados por la línea de investigación paleoambiental (Ratto et al. 2013 a). Todo el acervo material recuperado fue georreferenciado y adscripto espacialmente a distintos sectores del extenso barreal de La Troya que se extiende por, aproximadamente, $8 \mathrm{~km}$ lineales entre el río de La Troya, al Norte, y el río del Puesto, al Sur. Esto permitió segmentar el barreal en tres sectores: Sur (tramos 1, 2, 3), Centro (tramos 4 y 5) y Norte (tramos 6, 7 y 8); donde cada tramo mide aproximadamente $1 \mathrm{~km}$ lineal. Aunque los sectores son arbitrarios responden a la distribución espacial de la materialidad cultural registrada (Figura 1). Aclaramos que el registro material superficial, principalmente cerámico y lítico, es continuo a lo largo de la extensión del barreal, y su abundancia, distribución y composición puede consultarse en los informes técnicos (Ratto 2005 b, c, d), por lo que en este trabajo nos centramos en estructuras (arquitectura y hornos), más evidencia artefactual y bioarqueológica recuperada en las excavaciones sistemáticas y/o en los rescates realizados durante el monitoreo por movimientos de suelo con maquinaria pesada.

Por otro lado, se relevaron las colecciones arqueológicas depositadas en museos que cuentan con fichas de catálogo con proveniencia de los materiales en guarda y/o libretas de campo, y se realizó una lectura crítica de las publicaciones existentes (Lafone y Quevedo 1892, Lange 1892; González y Sempé 1975; Sempé 1977). Estos trabajos en conjunto generaron una información de base conformada por datos secundarios que, de acuerdo con su área de proveniencia, se integrarán con la información de base generada en forma sistemática. De esta manera, la articulación de datos primarios y secundarios, integrados a los procesos de formación naturales y culturales, son los que nos posibilitan realizar una lectura de la historia socioambiental del barreal de La Troya.

\section{Delineando los aspectos del entorno físico}

El río La Troya se inicia en la falda oriental del cerro Azufre (4400 msnm), en proximidades del límite interprovincial con La Rioja, y recorre unos $65 \mathrm{~km}$ lineales para desembocar en el río Abaucán (1363 msnm), frente a la localidad del Anillaco catamarqueño. Su abanico aluvional presenta paleocauces, fluvios fósiles, areniscas, gravas y extensos barreales, en algunos casos invadidos por sedimento eólico que conforma médanos de pequeña extensión. Estos barreales son producto del sedimento depositado luego de las crecientes del río La Troya. Sus aguas bajan de los cerros del occidente y son de un intenso color rojo la mayor parte del año por la alta carga de coloides y materiales limo-arcillosos que transporta como resultado de la erosión de las formaciones geológicas sedimentarias que se encuentran en la naciente del río (Rubiolo 2001; Tineo et al. 1999).

Los aluviones son frecuentes en estas zonas y se producen cuando un gran volumen de barro, rocas, limo, arena y agua se desplaza a gran velocidad y con alto poder destructivo por las quebradas, lo que produce que los materiales transportados desborden los cauces, invadan las áreas aledañas y produzcan inundaciones. Estos eventos tuvieron alta repetitividad anual y recurrencia en el tiempo, ya que el mismo Max Uhle advierte que los sitios arqueológicos están siendo destruidos por las crecientes de los ríos (Uhle 1893). A esto se suma la tala indiscriminada de algarrobos producida a partir del siglo XIX, relacionada con el desarrollo de la actividad minera, ferroviaria y maderera (Rojas 2013), que no solo contribuyó a acentuar la erosión y la formación de "barreales", sino que también provocó el ascenso de la napa freática favoreciendo la formación de salinas y salitrales.

Los estudios geológicos dan cuenta de que el abanico aluvial del río La Troya es un sistema de depósitos complejos con numerosos pulsos de distinta naturaleza e intensidad, cuya litología presenta diferencias por sectores. Al respecto, Ratto y colaboradores (2013 a) presentan la articulación de las observaciones geomorfológicas, las dataciones radiométricas y la evidencia arqueológica que posibilitaron identificar distintos eventos, entre los cuales algunos presentan características catastróficas, a saber:

a) El evento más reciente resultó en el arrastre por el agua de enormes bloques rocosos, muy irregulares, con diámetros máximos de cuatro metros, que quedaron dispuestos próximos a la barranca de la margen derecha del río La Troya. Los bloques aparecen dispersos y los 
de mayor tamaño se encuentran en las cercanías de la desembocadura del río. La geometría superficial y su disposición sugieren un depósito masivo de bloques, característicos de flujos de detritos masivos, con relación muy elevada sedimento-agua, que aconteció en tiempos posteriores a la construcción del sitio incaico de Batungasta, dado que se registraron grandes rocas depositadas por encima de los muros de la plaza incaica en el sector este del sitio. Este flujo masivo de alta energía provocó modificaciones graves en la instalación (derrumbe de muros, alteración de pisos de ocupación, entre otros).

b) En el sector central y distal del abanico se dispone un cuerpo de arenas y gravas por debajo de los grandes bloques del evento más reciente. Las arenas presentan las características propias del transporte fluvial, grano selección, estratificación cruzada y morfologías planares de los cuerpos sedimentarios. Las características sedimentológicas de la unidad arenosa sugieren transporte por corrientes acuosas tractivas muy energéticas con gran cantidad de carga y un flujo de arroyada más canalizado. La datación radiométrica de fragmentos de ramas contenidas dentro de la unidad de arena se ubica temporalmente alrededor del año 1250-1300 de la era (Ratto et al. 2013 a:57); por lo que se considera que fue anterior al primer evento masivo, de agua y grandes bloques, antes descripto. Este evento afectó a las ocupaciones previas a la edificación de Batungasta, impactada principalmente por el anterior, y de la aldea de LT-V50 (ver más adelante).

c) Los eventos más antiguos corresponden a las coladas de fangos (limo-arcilloso) que tuvieron amplia extensión areal, pero con diferencias por sectores dentro del amplio abanico del río La Troya. Las características de los tamaños irregulares de los grandes bloques del depósito y la ausencia de estructuras sedimentarias propias del transporte fluvial indicarían un transporte en masa de elevada viscosidad, propio de los flujos de lodos (mudflow). Sin embargo, estos eventos posiblemente sean consecuencia de distintos episodios que se sucedieron en el tiempo con diferente intensidad, los cuales no tenemos totalmente calibrados, pero si lo relacionamos con estratos arqueológicos contenidos dentro de éstos podemos tener una temporalidad relativa. Al respecto, en adyacencias del curso actual del río La Troya, sector Norte, la unidad limo-arcillosa se asocia con clastos aislados y fragmentos de materiales cerámicos, dispuestos en posición vertical y heterogénea; dicha unidad se ubica por debajo del estrato de grandes bloques. Unos 4 km al sur, en el área de Giusepe, se observa que el estrato limo-arcilloso está intercalado por dos lentes de ceniza con pequeños carbones, separadas una de otra por $10 \mathrm{~cm}$ de espesor, ambas asociadas con fragmentos cerámicos grises, de cocción reductora característicos de momentos de las sociedades aldeanas tempranas (Formativo). Ambas lentes fueron datadas y se ubican temporalmente alrededor del año 400 de la era (Ratto et al. 2013 a:58). Por lo que, se consideró que el estrato masivo arcilloso que se dispone por arriba de las lentes fue un evento que ocurrió antes de la instalación de la aldea formativa LT-V50, y posterior al que la afectó (ver punto b).

En resumen, en el área del abanico aluvial del río La Troya tuvieron lugar, a lo largo del tiempo, sucesivos episodios masivos de torrentes de barros y flujos de detritos de distinta intensidad y extensión. A estos episodios naturales se le suma el accionar de los pobladores locales que, con distintas intenciones, han alterado el sitio a lo largo del tiempo (excavaciones clandestinas, conformación de colecciones públicas y privadas como son los casos del Museo Municipal Robaudi y el privado Alanis, respectivamente, ambos en la ciudad de Tinogasta). Por lo tanto, puede afirmarse que el barreal estuvo y está sujeto a intensos procesos de formación, tanto de agentes naturales como culturales, no obstante, como veremos, el registro arqueológico superficial y subsuperficial da cuenta de su ocupación continua a lo largo del tiempo, a modo de un palimpsesto cultural producto de la acción de sociedades agropastoriles y estatales.

\section{La materialidad cultural del barreal de La Troya}

En esta sección presentamos los distintos tipos de sitios (residenciales, funerarios y productivos, alfareros y agrícolas), registrados en cada uno de los tres sectores arbitrariamente definidos del extenso barreal de La Troya (Figura 1). Algunos de los sitios cuentan con reportes en publicaciones previas, mientras que otros son inéditos; pero en uno y otro caso puntualizaremos en aquellos aspectos significativos que permitirán integrar la evidencia. Este aspecto es fundamental para delinear la historia socioambiental del barreal de La Troya desde las sociedades del primer milenio hasta momentos hispanoindígenas, ya que en cada uno de estos procesos se entretejieron relaciones entre personas, objetos y lugares.

\section{Sector Norte del barreal de La Troya (Figura 2)}

En la margen derecha del río La Troya fue construido el sitio arqueológico Batungasta (1.480 msnm). Presenta diversas estructuras arquitectónicas de formas rectangulares, circulares y poligonales, entre los que se hallan dos grandes plazas, recintos y encierres de recintos que definen sectores hipotéticamente abiertos. Los espacios públicos plazas, cubren una superficie de 30.000 $\mathrm{m}^{2}$ sobre la superficie total del asentamiento de 88.450 $\mathrm{m}^{2}$, cuya función en tiempos del inca estuvo relacionada con actividades festivas y de producción alfarera (Orgaz et al. 2007; Orgaz y Ratto 2015, 2016; Ratto et al. 2002). Esta última evidenciada por la existencia de cinco hornos para la cocción cerámica -cuya morfología tipo ojo de cerradura solo pudo identificarse en un caso- los que se ubican a $500 \mathrm{~m}$ al Sur y al Norte del ejido del sitio. Las dataciones radiométricas indican que su edificación fue en el siglo XV, pero continuó en época histórica (Orgaz y 


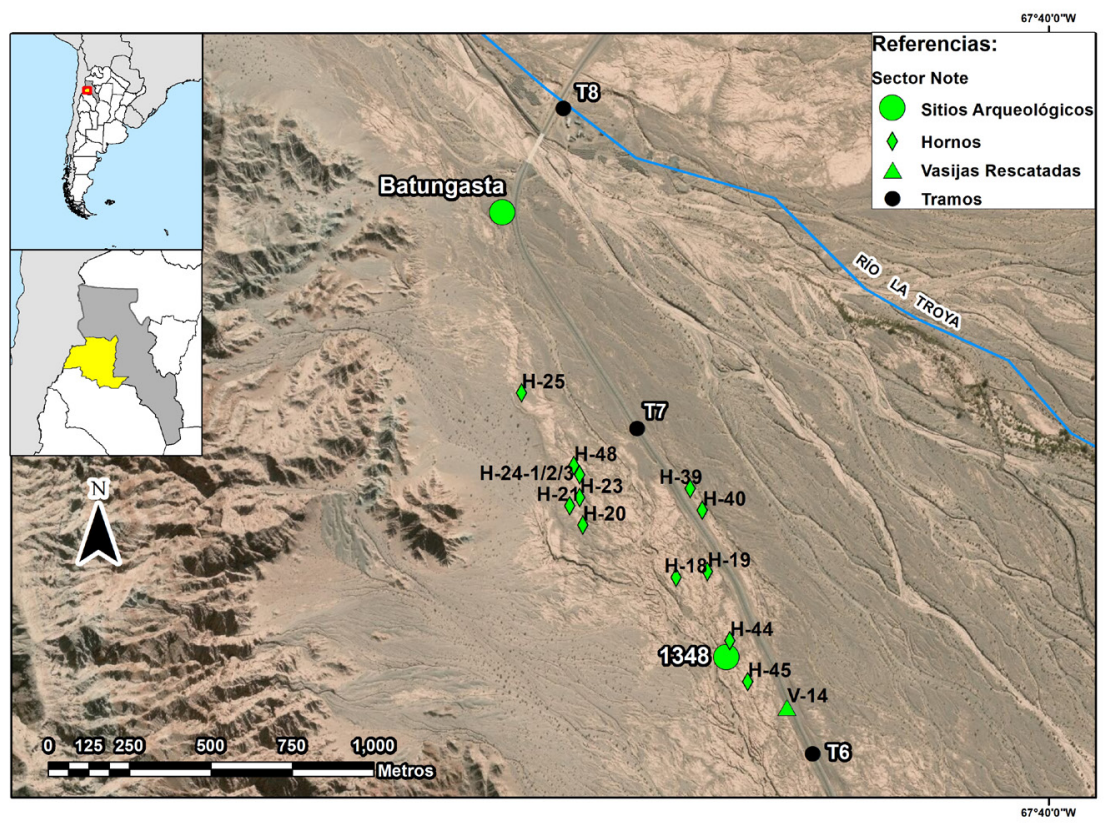

Figura 2. Sector Norte del barreal de La Troya (Tramos 8 y 7 )

Figure 2. North Sector of Barreal of La Troya (Sections 8 and 7)
Ratto 2015: Tabla 1). En el marco de la repavimentación de la RN60 se realizaron excavaciones en el sector Este del sitio que pusieron en relieve los intensos procesos de formación actuantes, dado que parte de las estructuras están en cimiento-muro pétreos expuestos (Ratto 2005 a y b). Al respecto, se destacan: (i) por un lado, la existencia de oquedades en el sedimento que se interpretaron como improntas de las bases ápodas de grandes ollas, que seguramente fueron enterradas para almacenar diferentes sustancias, y muy posiblemente extraídas en el marco de acciones vandálicas o no-sistemáticas, previas a nuestra intervención (Figura 3 A); y (ii) por otro, la recuperación de material óseo ecofactual cuya datación remite a la ocupación del espacio en el siglo IX-X (LP- 3284, radioulna de llama, $1140 \pm 80$ años AP, $\delta^{13} \mathrm{C}$-estimado- $-20 \pm 2 \%$, [cal AD 862: cal AD 1028], curva calibración SCHcal13, programa Calib 7.0.4). Este fechado es altamente significativo cuando lo integramos con otro tipo de evidencia material, especialmente cerámica, recuperada en el sitio Batungasta por Uhle (1893) y por González y Sempé (1975), quienes reportan la presencia de cantidades significativas de figurinas y de tiestos de estilos Aguada, respectivamente, que superan en proporción al material tardío-inca recuperado. Lo concreto es que nos encontramos ante un espacio multicomponente, habitado en el tiempo, pero cuya cultura material está sesgada por los procesos de formación culturales. Al respecto, la multitemporalidad de este espacio está representada, actualmente, en la periferia del sitio donde el registro superficial da cuenta de un palimpsesto cultural (Feely 2003).

Un kilómetro y medio al Sur de Batungasta se localiza el sitio 1348, que fuera descripto por Togo (1979) y adscripto a momentos incaicos por sus características arquitectónicas y registro cerámico en superficie. Al inicio de las investigaciones del PACh-A el sitio fue localizado, pero su estado de preservación era muy malo, por lo que poco más podemos aportar sobre lo ya dicho por el colega, con excepción del registro y documentación de 13 hornos, de los cuales siete tienen forma de ojo de cerradura con buena preservación y seis son de contorno indefinido por alta alteración (Figura 6 E). Se intervinieron tres estructuras, de contornos bien definidos, cuyos fechados remiten al siglo XIV y XV (Andreoni et al. 2018: Tabla 1). ${ }^{1}$ Asimismo, en las inmediaciones del sitio se recuperó una vasija ordinaria de base cónica, cuya morfología coincide con la de otras adscritas a estos momentos de ocupación del espacio (Feely 2010), rescatada en el marco de las tareas de monitoreo de movimiento de suelo del estudio de impacto (Ratto 2005 b). Aclaramos que en el sector Norte del barreal de La Troya no se registraron entierros de ningún tipo.

Sector central del barreal de La Troya (Figura 4) La evidencia material que proviene de este sector es escasa y surge de los estudios de impacto, producto del control realizado por los movimientos de suelo de la obra vial (Ratto 2005 b). A saber:

a) Por un lado, se relaciona con actividades de producción alfarera, representada por dos hornos, sin contornos definidos por su mal estado de preservación, por lo que no fueron intervenidos.

b) Por otro, contamos con información funeraria de tres entierros con restos esqueletales en muy mal estado de preservación, pero que por sus tamaños remiten a individuos adultos, aunque no cuentan con análisis bioarqueológicos de detalle. Dos entierros están asociados a piezas cerámicas de estilos tardíos en estado muy fragmentario. El otro se relaciona con

\footnotetext{
${ }^{1}$ Los hornos en cuestión son los denominados BATH-20, BATH-24/1 y BATH-24/2 (Andreoni et al. 2018: Tabla1).
} 


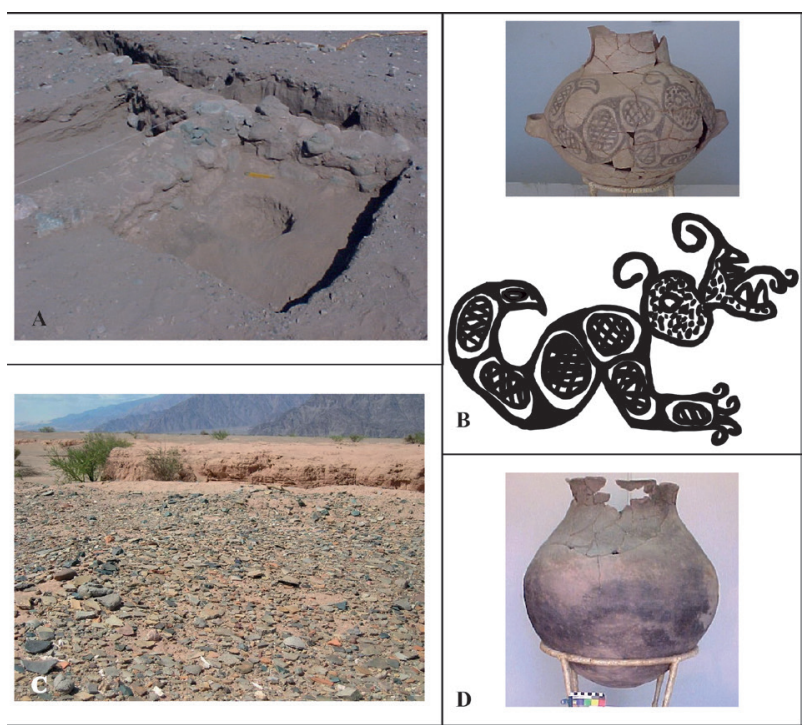

Figura 3. A. Improntas de vasijas registradas durante la excavación del sitio arqueológico Batungasta; B. Pieza estilo Aguada asociada a restos humanos; $C$. Sector de localización de la aldea LTV50; D. Vasija ordinaria recuperada en la aldea LTV50

Figure 3. A. Prints of vessels recorded during the excavation of Batungasta archaeological site. B. Aguada style vessel associated with human remains. C. Location of LTV50 village; $D$. Ordinary vessel recovered in LTV50 village

dos vasijas subglobulares compuestas, restringidas, de cuellos cortos y bordes evertidos, con dos asas en cinta horizontales, bases cóncavo-convexas y cocción oxidante; ambas presentan decoración pintada negro sobre ante que representan felinos con fauces abiertas y en posición de acecho (Figura 3 B). Es interesante que ambas piezas remiten al estilo cerámico Aguada por forma y lenguaje visual representado, pero se diferencian completamente de este, tal como está representado en el bolsón de Fiambalá (Feely 2010), tanto por la textura de sus pastas, que contienen abundante arena de grano medio, como por el acabado de sus superficies, que es alisado de mala factura. Otro aspecto relevante es que, durante la construcción de la línea de base del estudio de impacto (Ratto 2005 b), en la zona del hallazgo de las dos piezas Aguada asociada con los restos humanos, se registraron 30 pozos por acción vandálica, por lo que se infiere que fue un área con intensa alteración antrópica. Esto se relaciona con que $700 \mathrm{~m}$ al Norte se recuperó otra pieza de iguales características tecno-morfo-

Figura 4. Sector Central del barreal de La Troya (Tramos 6 y 5)

Figure 4. Central sector of Barreal of La Troya (Sections 6 and 5) decorativas, pero sin asociación con restos óseos.

Es interesante que la materialidad cultural de este sector del barreal para momentos de las sociedades del primer milenio está representada tanto para el Período Medio como para el Temprano. Al respecto, en los trabajos de control se rescató una jarra miniatura, subglobular, inflexionada, de borde evertido, base cóncava-convexa, cocción mixta y superficie externa pulida, de típica factura Aguada, además de las tres piezas antes mencionadas; y una escudilla hemiesférica grande, no restringida, simple, cocción reductora, con decoración al pastillaje y pulido en líneas, que corresponde a lo que Sempé (1976) definió como estilo cerámico Saujil, presente en la región desde el inicio del primer milenio de la era. La evidencia subsuperficial cerámica que remite a distintos momentos del desarrollo cultural del barreal es coincidente con el perfil del registro de fragmentos cerámicos recuperado en superficie (Ratto 2005 b). Finalmente, en el sector central del barreal no se registró evidencia arquitectónica, ni se cuenta con fechados radiométricos absolutos.

\section{Sector Sur del barreal de La Troya (Figura 5)}

Es en este sector donde encontramos la mayor asociación de evidencia cultural que da cuenta de la ocupación de este espacio en cuenta larga, tanto por las sociedades del primer milenio como por la tardía-inca, la que en ambos casos surge como producto de los estudios de impacto por obras viales y emprendimientos agrícolas (Ratto 2005 a, b, c, d). En este sector se registró una aldea, 24 hornos para la cocción de alfarería y cinco entierros de párvulos. Los momentos aldeanos están representados por el sitio de residencia permanente y evidencia de producción alfarera y funebria; mientras que los tardíos-inca solo por funebria. Además, en el sector sur, pero en la margen izquierda del barreal se localiza el área agrícola de los Canchones El Puesto (Orgaz et al. 2014).

La aldea LT-V50 presenta un registro superficial cerámico

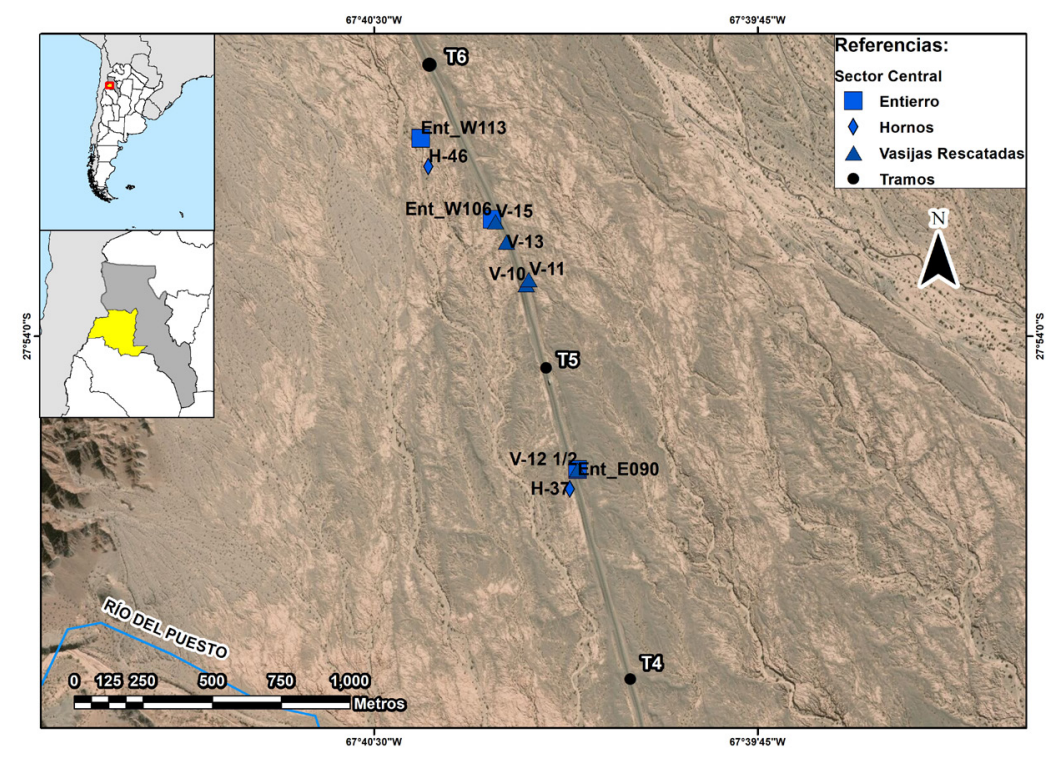

ISSN 1852-060X (impreso) / ISSN 1852-4826 (electrónico) 
Figura 5. Sector Sur del barreal de La Troya (Tramos 4, 3 y 2)

Figure 5. South sector of Barreal of $L a$ Troya (Sections 4, 3 and 2)

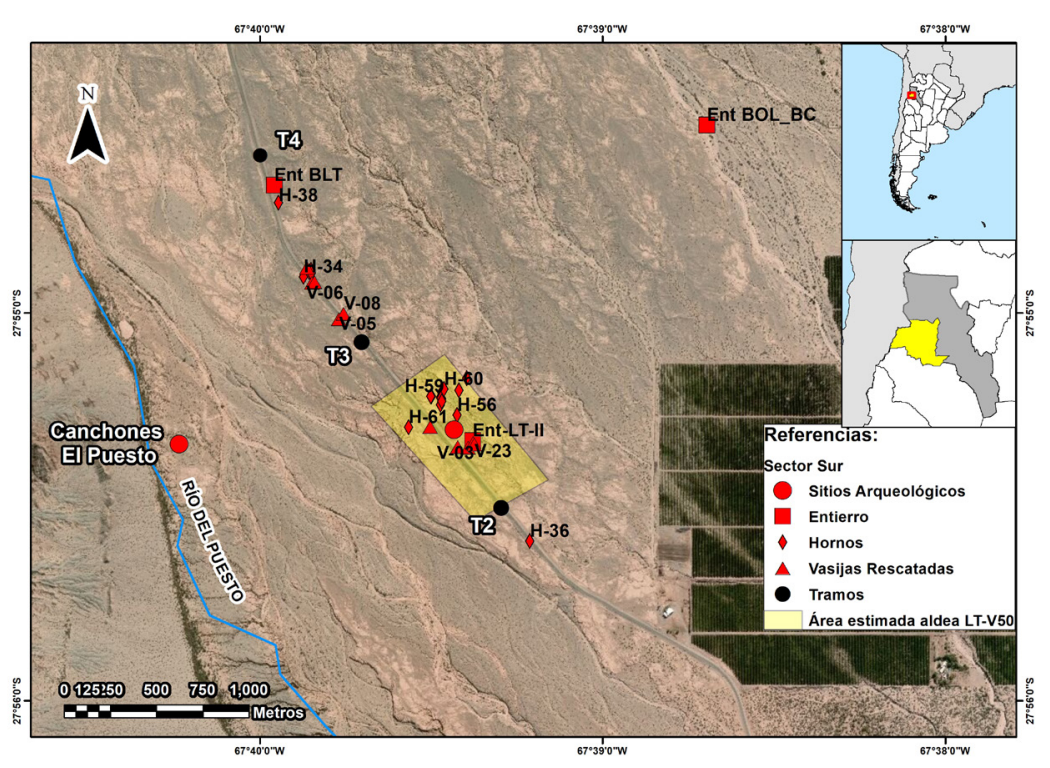

continuo, con densidades diferenciales, que forma un palimpsesto cultural que se extiende por $900 \mathrm{~m}$ en sentido de la traza de la RN60 y 130 m al Este de esta (Figura 3 C). El complejo arquitectónico construido con materiales de tierra (tapia) se encuentra en muy mal estado de preservación debido a la acción de agentes fluvio-eólicos, pero cuenta con dos fechados radiométricos que lo ubican entre los años 641-784 de la era y parte de su arquitectura fue descubierta aplicando métodos geofísicos (Feely y Ratto 2009; Ratto et al. 2013 b). Dentro de este espacio se encuentra el perfil muestreado en el área de Giusepe (ver más atrás) cuyas dos dataciones remiten al periodo temporal comprendido entre los años 327 y 433 de la era (Ratto et al. 2013 a:58); por lo que puede decirse que esta instalación tuvo un ciclo de vida que se extendió por casi 500 años, situación que no es llamativa en la región, si consideramos que la aldea de Palo Blanco, ubicada 65 $\mathrm{km}$ lineales al Norte, tuvo un desarrollo cultural de mil años (Ratto et al. 2019). Asociados a la aldea, dentro de un radio de $200 \mathrm{~m}$ aproximadamente, se registraron 14 hornos, de los cuales 10 presentan forma circular y el resto indefinida debido al mal estado de preservación. Cuatro fueron excavados, entre los mejor preservados, y de tres se obtuvieron dataciones absolutas que los ubican entre los años 656 y 939 de la era (Andreoni et al. 2018: Tabla 1). ${ }^{2}$ Dentro del área de la aldea se rescataron cinco piezas cerámicas ordinarias, de forma subglobulares compuestas o inflexionadas, restringidas, con bases cónica o subcónicas, cocción reductora, y manchas de hollín, excepto un caso (Figura 3 D). Este conjunto refuerza la función residencial de la aldea donde se realizaron tanto actividades de cocción de comidas como el almacenamiento de variados recursos. También se recuperó el entierro de un perinato, La Troya-II, que

\footnotetext{
2 Los hornos en cuestión son los denominados BATH-35 y BATH-36
} (Andreoni et al. 2018: Tabla1). Luego obtuvimos un fechado del horno BATH-51 (LP- 3334; $1270 \pm 50$ años AP, $\delta^{13}$ C (estimado): $-24 \pm 2 \%$, [cal AD 692: cal AD 882], 1 sigma). fue dispuesto debajo de un muro de tapia de una de las estructuras de la aldea, a modo de ofrenda fundacional.

Ochocientos metros al Norte de la aldea de LT-V50 y mil metros al nordeste, la materialidad cultural se reduce solo a la presencia de hornos y de entierros, cuyas temporalidades corresponden tanto a las sociedades del primer milenio como tardía. De los 10 hornos registrados en estos espacios, cuatro tienen forma circular y seis indefinida debido a su mal estado de preservación (Figura $6 \mathrm{D})$. Dos fueron excavados y solo de uno se cuenta con fechado radiométrico que remite a los años 681-746 de la era (Andreoni et al. 2018: Tabla 1). ${ }^{3}$ También se rescataron dos piezas cerámicas, una ordinaria y otra decorada con pintura roja, que por sus características tecno-morfodecorativas responde a las sociedades del primer milenio. En cuanto a la funebria, para estos momentos, está representada por un entierro rescatado debajo del asfalto original de la RN60, que consiste en material óseo en muy mal estado de preservación, asociado con tres piezas cerámicas del Horizonte gris (Figura 6 A): (i) un plato pulido en líneas, contorno simple no restringido, base cóncava convexa y borde curvo; (ii) una olla pequeña no decorada de forma esferoidal, restringida de contorno simple, de base cóncava-convexa y forma de borde indeterminado, y (iii) un puco compuesto, decoración incisa, no restringido, de borde recto y base cóncava convexa (Ratto 2005 b). ${ }^{4}$ Si relacionamos la presencia de esta materialidad cultural con la fragilidad de la arquitectura en tierra, principalmente el colapso de muros y la mezcla con la matriz natural del sedimento, no es descabellado pensar que la aldea LT-V50 pudo haber presentado una extensión mayor a la previamente estimada. Tampoco se descarta que estos espacios, con evidencias de multitemporalidad -formativo y tardío-, hayan sido sujetos a mayores

\footnotetext{
3 El horno en cuestión es el denominado BATH-31/2 (Andreoni et al. 2018: Tabla1).

${ }^{4}$ Se trata de las piezas denominadas V7/1, V7/2 y V7/3 (Ratto 2005 b).
} 
alteraciones por parte de agentes culturales, dado que a escasos $200 \mathrm{~m}$ del entierro recuperado debajo del asfalto de la RN60, antes mencionado, se rescataron nueve piezas con características tecno-morfo-decorativas típicas de las sociedades agroalfareras tardías, mayormente de tamaño grande, ordinarias, con y sin manchas de cocción, que no presentaban asociación con otro tipo de evidencia.

La ocupación de este sector del barreal de La Troya para momentos tardíos con contacto incaico (Orgaz y Ratto 2015), está representado solo por funebria y se trata de entierros de párvulos que fueron reportados en trabajos previos (Ratto et al. 2007, 2014, 2016) (Figura 6 B y C). Las características de estas inhumaciones presentan diferencias: (i) uno de ellos, denominado Bebé de La Troya, está asociado a piezas cerámicas que comparten estilos Sanagasta y Belén (contenedor, tapa de urna y piezas del acompañamiento) y el fechado sobre material óseo humano remite a las primeras décadas del siglo XV; (ii) en el segundo caso, denominado Bebé del Cauce, el contenedor es una urna Sanagasta y el fechado del párvulo también remite a los inicios del siglo XV; y (iii) por último, el Bebé de los Olivares fue recuperado en tierra y su fechado remite a fines del siglo XIV; consideramos que su situación es producto de un acto vandálico en el cual se extrajo la urna que lo contenía dejando los restos del párvulo in situ. En las áreas donde fueron rescatadas estas inhumaciones se registraron gran cantidad de pozos producto de acciones vandálicas.

\section{Delineando el proceso socioambiental del barreal de La Troya: espacio y tiempo}

No debe extrañarnos el uso de las geoformas barreales a lo largo del tiempo, ya que solo tenemos que remitirnos a la llamada Cultura de los Barreales, acuñada por Debenedetti (1931) para reemplazar al término Draconiana, y que remitía a esos ambientes sedimentarios fluviales de suelos desnudos y erosionados, en los cuales se registraban con mayor frecuencia restos cerámicos de lo que luego se denominó cultura de la Aguada (González 1961-1964). Es en ese trabajo donde González establece y contextualiza su área de dispersión en las provincias de Catamarca, la Rioja y Norte de San Juan, redefiniendo su desarrollo temporal con posterioridad a Ciénaga, y la relaciona espacialmente con la existencia de estas geoformas de origen fluvial. Es también interesante que la ocupación de estos barreales continúa para momentos tardíos e incas en las provincias de San Juan (García 2010; Michieli 2008) y La Rioja (Callegari et al. 2015; Iniesta y Bárcena 2014), donde reportan altas dispersiones de material cerámico, la existencia de una arquitectura en tierra (adobe, tapial) y/o perecedera (quincha de cañas revocadas con barro) montada sobre cimientos de rocas, y la presencia de hornos destinados a la manufactura cerámica.

Quizás, la mayor diferencia del barreal de La Troya con

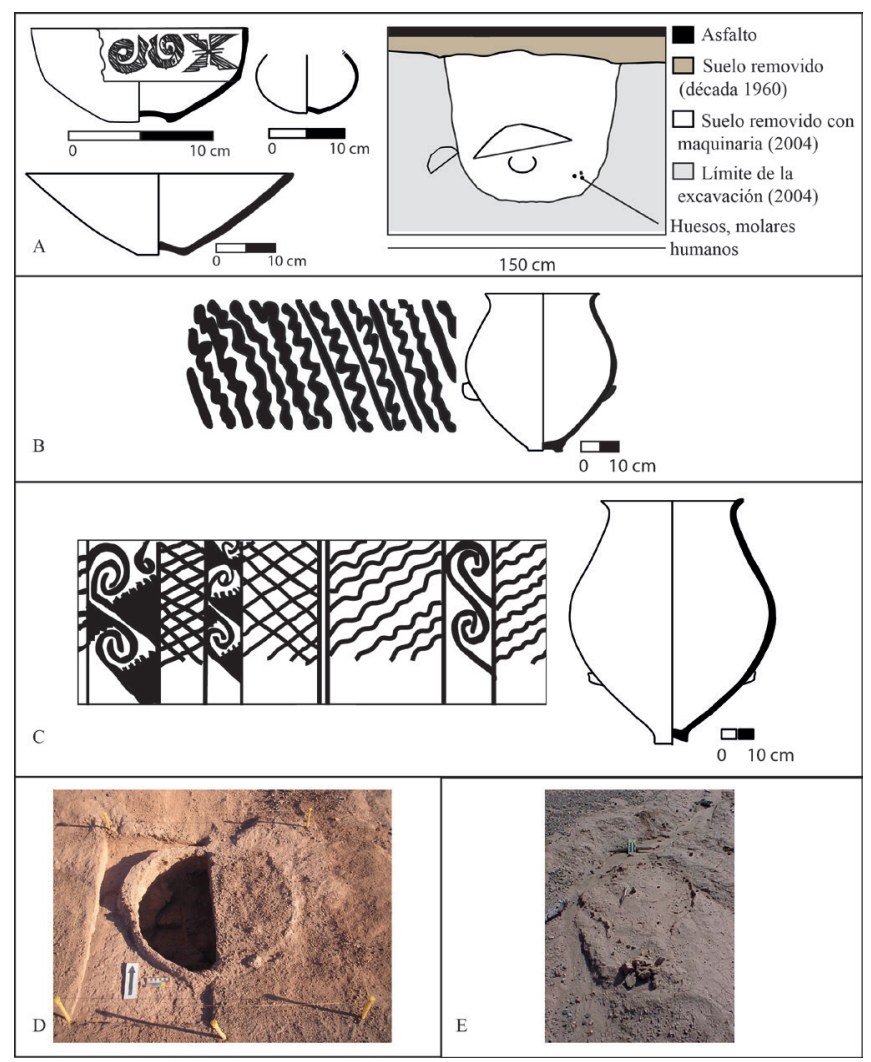

Figura 6. A. Izquierda: piezas rescatadas debajo del asfalto (RN60) en asociación con restos óseos humanos, derecha: croquis de la posición de los hallazgos; B. Contenedor del entierro del Bebé del Cauce; C. Contenedor del entierro del Bebé de La Troya; D. Horno de forma circular; E. Horno en forma de pera u ojo de cerradura

Figure 6 A. left: vessels recoverd under the asphalt (RN60) in association with human remains; right: skecth of the discovery; B. Burial container of Bebé del Cauce; C. Burial container of Bebé de La Troya; D. Circular firing structure; E. Pear shaped or keyhole firing structure

respecto a los de las provincias de San Juan y La Rioja, es que contamos con dataciones radiométricas que dan cuenta de su habitar desde el siglo IV hasta el XVII por parte de las sociedades del primer milenio, la incaica y las poblaciones locales movilizadas y finalmente la española y los nuevos traslados de pueblos el marco de las encomiendas (Ratto y Boixadós 2012; Orgaz y Ratto 2013). Es interesante que, a pesar de los eventos catastróficos y las intensas crecidas de los ríos, la gente se siguió asentando en el área del barreal. Al respecto, en las libretas y cartas de Max Uhle se especifica que en el sitio Huatungasta (Batungasta) solo recuperaron dos fragmentos cerámicos incaicos (plato pato y aríbalo) a pesar de constituir la instalación más grande y emblemática de la región. Esta situación seguramente está relacionada con los intensos procesos naturales, especialmente las asiduas e intensas crecidas de los ríos producto de la dinámica fluvial, que son la causante del deterioro y destrucción de los sitios arqueológicos emplazados en esos espacios, tal como ya fuera alertado por Lange 
(1892) y Max Uhle en sus libretas de campo (Ratto 2015; Ratto et al. 2013 a). En contraposición, es Ilamativa la cantidad de material fragmentario y entero depositado en el Museo Etnológico de Berlín (Alemania) que corresponde a las sociedades del primer milenio, especialmente de filiación cultural Aguada, donde las figurinas y hornillos de pipas tienen una alta representación; y también de materiales de las sociedades agroalfareras del Período Tardío, principalmente con características tecno-morfodecorativas características de la cerámica Belén (Orgaz y Ratto 2020; Ratto 2015). Estos resultados del siglo XIX son coincidentes, en términos relativos, con las relaciones entre materiales en superficie de distintos momentos del desarrollo cultural que reportaron González y Sempé (1975) y Feely (2003) para la década de 1960 y 2000, respectivamente; los cuales provienen del área del sitio Batungasta y su periferia inmediata, como así también de los hallazgos recuperados en las excavaciones realizadas en ese sitio donde el material de las sociedades del tardío supera al de filiación incaica (Orgaz et al. 2007; Ratto 2005 a y b). Estas observaciones no son hechos menores, ya que están dando cuenta de la importancia de articular información de distintas fuentes, primarias y secundarias, para acercarnos a delinear los procesos del pasado con el menor sesgo posible. Las colecciones permiten contextualizar en cuenta larga la escasez o la abundancia de determinados materiales, por ejemplo, en nuestro caso fue importante conocer que la escasez de materiales incaicos en Batungasta fue registrada tanto por Uhle en 1893 como en nuestros trabajos realizados en las décadas de 1990-2000. Por lo tanto, la baja abundancia no obedece a procesos de formación naturales ni culturales, sino más bien pueden estar relacionados con las relaciones construidas entre el inca con las poblaciones anexadas.

Cambiando el eje de la discusión, otra de las características de los barreales es la construcción de viviendas con materiales de la tierra (adobes, tapia, quincha con revoque de barro). Al respecto, en el barreal de La Troya se observa que en el sector Norte domina el adobe como técnica constructiva para momentos hispano-indígenas, montado sobre los muros pétreos incaicos del sitio Batungasta, mientras que en el sur se utilizó la tapia en los muros de la aldea LT-V50 del primer milenio. Es interesante que en el sector central no se registraron sitios residenciales, pero sí entierros de adultos asociados con piezas cerámicas que por sus características tecno-morfo-decorativas remiten tanto a las sociedades del primer milenio como de momentos tardíos. Es altamente probable que estos espacios centrales del barreal funcionaran como lugares de funebria, fuera de los espacios residenciales, tanto para las primeras poblaciones aldeanas como para aquellas movilizadas por el inca en el marco de sus estrategias de dominación (Orgaz y Ratto 2013, 2015). Sin embargo, en función de lo registrado en los barreales de San Juan y La Rioja, no podemos descartar que las viviendas de momentos preincaicos hayan sido construidas con materiales muy perecederos, del tipo quincha, y no llegaran a preservarse. De esta manera, lugares de funebria o viviendas perecederas se presentan como hipótesis alternativas, pero, quizás, el registro de más de 30 pozos producto de vandalismo, en una pequeña área de este sector del barreal, pueden estar dando cuenta de que en esos lugares se buscaron y destruyeron decenas de tumbas para recuperar, principalmente, las piezas cerámicas de los acompañamientos, que pasaron a formar parte del tráfico de piezas o de colecciones de particulares de los pobladores locales. Otra evidencia que aporta a la hipótesis de lugares de funebria es la recuperación de las piezas cerámicas, con clara reproducción de imágenes que remite al estilo Aguada, pero con pérdida de los saberes tecnológicos característicos de esa entidad, ya que en nuestro caso las piezas presentan pastas con textura finamedia, los acabados de superficie son menos elaborados y los contornos son asimétricos, lo que las diferencia de los estilos tecnológicos Aguada registrados en la región (Feely 2010). Esto podría estar dando cuenta de la resignificación de imágenes en momento posteriores al desarrollo de "Aguada", como también fue registrado en el caso del arte rupestre en el Campo de Grabados de Guanchincito que responde a momentos tardío-inca en la historia regional (Basile y Ratto 2014; Basile y Gordillo 2019). Por otro lado, los campos de cultivo identificados se emplazan en el sector oeste del barreal, con respecto a la ruta que lo biseca, tanto los asociados con Batungasta (sector norte) como con la aldea de LT-V50, específicamente los Canchones El Puesto (Figura 5).

Otra característica de estos barreales es la presencia de hornos para la cocción de piezas cerámicas, como fue documentada en sitios de La Rioja (De la Fuente 1994; Spengler 2017; Wachsman et al. 2020) y otros casos no tan seguros que provienen de la provincia de San Juan, pero que por forma y características son similares a los registrados y excavados en el área del barreal de La Troya (Caletti 2005; Feely 2011). Al respecto, también el barreal de La Troya presenta un caso particular, dado que la perfila como un espacio destinado a la manufactura cerámica a lo largo del tiempo. Los hornos de forma circular tienen mayor frecuencia en el sector Sur del barreal, donde fue emplazada la aldea LT-V50 del primer milenio; mientras que los de forma de ojo de cerradura o pera se construyeron en mayor proporción en el sector Norte. Los fechados radiométricos dan cuenta que los circulares están presentes hasta el año 1000 de la era, y luego son reemplazados por los ojos de cerradura, existiendo un breve momento de coexistencia (Andreoni et al. 2018).

En resumen, una característica de los sitios arqueológicos emplazados en estas geoformas de barreales es su mal estado de preservación, en gran parte por los intensos procesos de formación naturales y culturales actuantes, los primeros de origen fluvial y los segundos por el avance de áreas residenciales rurales, además del vandalismo. Si bien todo el barreal de La Troya ha sufrido intensos 
procesos postdepositacionales, creemos que actuaron diferencialmente en los distintos sectores definidos. La mayor cantidad de evidencias proceden de los sectores Norte, donde se ubican los sitios de filiación incaica Batungasta y 1348, y Sur, donde se encuentra la aldea LTV50 correspondiente a las sociedades del primer milenio, mientras que en el sector central no se han registrado estructuras habitacionales, estimándose que fue un lugar para funebria. Sin embargo, todo el espacio del barreal da cuenta de su reocupación a lo largo del tiempo, que ha quedado evidenciada tanto por el registro de los estilos cerámicos, los entierros, las estructuras de combustión y los fechados respectivos.

En la realidad multicomponente del barreal de La Troya destaca el papel que tuvieron sus barros fango-arcillosos en la historia socioambiental regional (Orgaz y Ratto 2016, 2020; Ratto et al. 2002, 2004, entre otros). El Alfar de La Troya, el pago en ofrendas para extraer los barros, las aguas rojas del río La Troya y la construcción del sitio Batungasta fueron relacionados para comprender las estrategias del incario en la construcción de las relaciones sociales, políticas y religiosas con las poblaciones anexadas y movilizadas, y particularmente con la minería no-metalífera desarrollada en el Alfar a lo largo del tiempo. Al respecto, se considera que este escenario social impregnado de significados fue posible por la pervivencia de una memoria social, que fue la que posibilitó la transmisión del valor de este espacio a través de diferentes modos de reproducción: las figurinas de arcilla para las sociedades del primer milenio y la monumentalización con la construcción del sitio Batungasta (Orgaz y Ratto 2015, 2016, 2020).

Por todo lo expuesto en este trabajo podemos afirmar que el área de La Troya fue un espacio con historia y persistente en tiempos prehispánicos, pero lo interesante es que continuó siéndolo durante la conquista española, principalmente por la reclamación del sitio incaico Batungasta y la conformación de las encomiendas. Al respecto, Gregorio de Luna y Cárdenas asumió como encomendero en 1635 y en su título consta la merced de "Batungasta, Fiambalá, Tucumanahao y Antapa" (Ratto y Boixadós 2012). Pero esta persistencia también llega tiempos actuales cuando cada 1 de agosto las comunidades originarias se dan cita en el área de La Troya para honrar a la Pachamama y realizar sus rituales (comunicación personal Martina Marcial mayo 2019). Un espacio resignificado como lugar por las sociedades del primer milenio, la incaica, la española y la actual, no es un hecho menor. Es interesante mencionar el manejo del lenguaje que realizaron Samuel Lafone Quevedo y Adán Quiroga cuando se refieren a este lugar como rodeado de wakas y que fue un templo u oráculo, respectivamente, quedando claro que la vitalidad de estos lugares no pasó desapercibida para ambos pioneros (Orgaz y Ratto 2020).

Don Torcuato, 18 de abril de 2020

\section{Agradecimientos}

A la Universidad de Buenos Aires, Secretaría de Ciencia y Técnicas por financiar parte de las investigaciones. Al Ingeniero Fabián Guevara, jefe de obra de la Empresa Vialmani Construcciones SA en la repavimentación del tramo El Puesto-La Troya en la RN60 durante los años 2003-2004. A Luis Coll por la confección de los mapas. A las/los evaluadores anónimos cuyos comentarios aportaron para la claridad y fundamentos del manuscrito.

\section{Referencias bibliográficas}

Andreoni, D., B. Marconetto, V. Mors y N. Ratto. 2018. Selección y manejo de recursos forestales en la región de Fiambalá (departamento Tinogasta, Catamarca). Estudios Atacameños 57:7:24.

Basile, M. y N. Ratto. 2014. Images and memory: the case of the field of engravings of Guanchincito (ca. 1250-1400 ad, Catamarca, Argentina). En Theory, rock art and heritage. Proceedings of the xvi World Congress International Union of Prehistoric and Protohistoric Sciences (uispp), Volumen 11, pp. 31-37. Cambridge: bar International Series 2659.

Caletti, S. 2005. Tecnología de cocción de piezas de arcilla. Un caso de estudio: Batungasta, Dpto. Tinogasta, Catamarca, Argentina. Tesis de Licenciatura de la Escuela de Arqueología de la Universidad Nacional de Catamarca. Ms.

Callegari, A., M. E. Gonaldi, G. Spengler, M. G. Rodríguez, M. E. Aciar, R. Pappalardo y M. L. Wisnieski. 2015. Tras las huellas del Formativo. Norte de la provincia de La Rioja. En M. A. Korstanje, M. Lazzari, M. Basile, F. Bugliani, V. Lema, L. Pereyra Domingorena y M. Quesada (eds.), Crónicas materiales precolombinas. Arqueología de los primeros poblados del Noroeste argentino, pp. 247-275. Sociedad Argentina de Antropología. Buenos Aires.

Criado Boado, F. 1993. Límites y posibilidades de la Arqueología del Paisaje. SPAL 2: 9-55.

David, B. y J. Thomas. 2008. Landscape archaeology: introduction. En B. David y J. Thomas (eds.), Handbook of Landscape Archaeology, pp. 27-43. Left Coast Press, Walnut Creek, California.

Debenedetti, S. 1931. L'ancienne civilisation des Barreales. Ars Americana 2, París.

De La Fuente, G. 2007. Producción y tecnología cerámica en Batungasta. Estandarización, especialización y procedencia (Valle de Abaucán, Depto. Tinogasta, Pcia. de Catamarca, Argentina). Tesis Doctoral de la Universidad Nacional de La Plata. Ms. 
De la Fuente, R. N. 1994. Algunos problemas arqueológicos en el Norte Chico de la provincia de La Rioja. Rumitacana: Revista de la Dirección Provincial de Antropología de Catamarca 1:15-22.

Feely, A. 2003. Propiedades del registro y variabilidad tecno-morfológica cerámica: vía de análisis para acceder a la funcionalidad de sitio arqueológico de Batungasta (Dto. Tinogasta, Catamarca). Tesis de Licenciatura de la Facultad de Filosofía y Letras de la Universidad de Buenos Aires. Ms. Consulta en: http://cambiocultural.homestead. com/files/tesis_impresion.pdf

Feely, A. 2010. Tradición cerámica y límites sociales en el bolsón de Fiambalá (Dto. Tinogasta, Catamarca). Tesis Doctoral, Facultad de Filosofía y Letras, Universidad de Buenos Aires, Buenos Aires. Disponible para consulta en el Repositorio Digital Institucional de la UBA. http://repositoriouba.sisbi.uba.ar/gsdl/cgi-bin/library. cgi?a=d\&c=afimaster\&d=1303_oai

Feely, A. 2011. Caracterización de estructuras de combustión de doble cámara para la cocción de artefactos cerámicos en La Troya (Tinogasta, Catamarca). Relaciones de la Sociedad Argentina de Antropología XXXVI: 325330.

Feely, A. 2012. El concepto de estilo tecnológico cerámico y su aplicación en un caso de estudio: los grupos formativos del oeste de Tinogasta (Catamarca). Arqueología 18: 49-75.

Feely, A. y N. Ratto. 2009. Variaciones de los conjuntos cerámicos de unidades domésticas: aldeas y puestos formativos del bolsón de Fiambalá (ca. 1500-1300 A.P.). En N. Ratto (comp.) Entrelazando Ciencias: Sociedad y ambiente antes de la conquista española, pp. 99-129. EUDEBA. Buenos Aires.

Fernández-Turiel, J. L., F. J. Pérez-Torrado, A. RodríguezGonzález, J. Saavedra, J. C. Carracedo; M. Rejas, A. Lobo, M. Osterrieth, J. I.Carrizo, G. Esteban, J. Gallardo, N. Ratto. 2019. The large eruption 4.2 ka BP in Cerro Blanco, Central Volcanic Zone, Andes: Insights to the Holocene eruptive deposits in the southern Puna and adjacent regions. Estudios Geológicos 75(1):1-31

García, A. 2010. Arqueología Prehistórica de San Juan. Editorial EFU.

González, A. R. 1961-64. La Cultura de La Aguada del N.O.A. Revista del Instituto de Antropología. Facultad de Filosofía y Humanidades. Córdoba, Tomo II, pp. 2-21.

González, A. R. y M. C. Sempé. 1975. Prospección arqueológica en el valle de Abaucán. Revista del Instituto de Antropología Serie 2: 7-32. Tucumán.
Gordillo, I. y M. Basile. 2019. Los unos y los otros: Contraposición y reflexiones sobre universos expresivos del NOA prehispánico. Boletín del Museo Chileno de Arte Precolombino 24(1):153-179.

Iniesta, M. L. y J. R. Bárcena. 2014. Investigaciones arqueológicas sobre las sociedades tardías del valle de Guandacol (Departamento Felipe Varela, oeste de La Rioja): espacio, estilos tecnológicos cerámicos y cronología. Arqueología 20 Dossier: 61-82.

Lafone Quevedo, S. 1892. El pueblo de Batungasta. Anales del Museo de La Plata II: 7-10.

Lange, G.1892. Las ruinas de pueblo de Watungasta. Anales del Museo de La Plata II: 3-5.

Michieli, C. 2008. Investigaciones arqueológicas sobre el período agropecuario tardío en la margen derecha del río Castaño (Calingasta, San Juan). Relaciones de la Sociedad Argentina de Antropología XXXIII, 2008. Buenos Aires.113-131-

Orgaz, M., A. Feely, y N. Ratto. 2007 La cerámica como expresión de los aspectos sociopolíticos, económicos y rituales de la ocupación Inka en la puna de Chaschuil y el valle de Fiambalá (Departamento Tinogasta, Catamarca, Argentina). En A. Nielsen, M.C. Rivolta, V. Seldes, M. Vázquez, y P. Mercolli (comps.), Procesos sociales Prehispánicos en el Sur Andino. La vivienda, la comunidad y el territorio, Tomo 1, pp. 239-250. Colección Historia Social Precolombina. Editorial Brujas, Córdoba

Orgaz, M. y N. Ratto. 2015. Estrategias de ocupación incaica en el sur del Noroeste Argentino (Departamento Tinogasta, Catamarca): la apropiación de paisajes sagrados y la memoria social. Revista Nawpa Pacha. Journal of Andean Archaeology 35 (2):217-235.

Orgaz, M. y N. Ratto. 2016. Aguas turbias, campos fértiles. La geografía sagrada del estado Inca en la región de Fiambalá, Tinogasta, Catamarca, Argentina. En R. Sandrine y B. Sittler (eds.), Water as a morphogen in Landscapes - L'eau comme morphogène dans les paysages, pp. 95- 104. UISPP PROCEEDINGS SERIES, UISPP - International Union of Prehistoric and Protohistoric Sciences, Archaeopress, British Archaeological Reports, Oxford

Orgaz, M. y N. Ratto. 2013. Fragmentos del pasado en la ocupación incaica del oeste tinogasteño (Catamarca). En N. Ratto (comp.), Delineando prácticas de la gente del pasado: Los procesos sociohistóricos del oeste catamarqueño, pp.311-333. Sociedad Argentina de Antropología, Buenos Aires.

Orgaz, M. y N. Ratto. 2020. Minería de las arcillas en tiempos prehispánicos (departamento Tinogasta, 
Catamarca, Argentina). Estudios Atacameños. En prensa.

Orgaz, M., N. Ratto y L. Coll. 2014. Aportes para la construcción de los paisajes agrícolas en la región de Fiambalá, Tinogasta, Catamarca: nuevas evidencias. Relaciones de la Sociedad Argentina de Antropología XXXIX (1): 79-94.

Raffino, R., R. Alvis, L. Baldini, D. Olivera y G. Raviña. 1983-1985. Hualfin-El Shincal- Watungasta. Tres casos de urbanización inka en el NOA. Cuadernos del Instituto Nacional de Antropología 10: 425-458.

Raffino, R., L. Baldini, D. Olivera y R. Alvis. 1984. Hualfín, El Shincal y Watungasta, tres casos de urbanización inca en el N.O. argentino. Cuadernos del Instituto Nacional de Antropología 10: 425-455.

Raffino, R. 1993-1998. Réquiem por Watungasta. Xama 6-11:113-126.

Raffino, R. 1995. Inka road research and Almagro's route between Argentina and Chile. Tawantinsuyu 1: 36-45.

Ratto, N. 2005 a. Estudio de Impacto Arqueológico por la pavimentación de la RN 60 y construcción de dos puentes -Sector El Puesto/La Troya- (departamento Tinogasta, Catamarca, Argentina): Etapa Construcción, 290 pp. Presentado a la empresa Vialmani Construcciones s.a. y Dirección de Antropología de la provincia de Catamarca, enero 2005. Ms.

Ratto, N. 2005 b. La Arqueología del Bolsón de Fiambalá a través de los Estudios de Impacto (dpto. Tinogasta, Catamarca, Argentina). En: Actas dos I Jornadas Internacionais Vestígios do Passado. AGIR - Associação para a Investigação e Desenvolvimento Sócio-cultural. Lisboa. Disponible en: http://proyectopacha.com.ar/ wp-content/uploads/2013/06/2005-Cong-2005-RattoAGIR-Portugal-2005.pdf

Ratto, N. 2005 c. Estudio de impacto arqueológico en Colonia Anillaco: predio Giusepe 2 para la plantación de olivares (dpto. Tinogasta, Catamarca, Argentina), 78 pp. Presentado a la Escuela de Arqueología (UNCa), Dirección de Antropología Catamarca y Dirección de Colonización del Ministerio de Producción de la Provincia de Catamarca. Julio 2005. Ms.

Ratto, N. 2005 d. Estudio de impacto arqueológico en Colonia Anillaco: predio Giusepe 3 y 4 para la plantación de olivares (dpto. Tinogasta, Catamarca, Argentina), 48 pp. Presentado a la Escuela de Arqueología (UNCa), Dirección de Antropología Catamarca y Dirección de Colonización del Ministerio de Producción de la Provincia de Catamarca. Noviembre 2005. Ms

Ratto, N. 2010. Arqueología y la Evaluación de Impacto
Ambiental. Revista Xama 19-23: 357-376.

Ratto, N. 2013. A modo de introducción: la articulación de estudios arqueológicos, paleoambientales e históricos en el oeste tinogasteño (Catamarca). En N. Ratto (comp.), Delineando prácticas de la gente del pasado: Los procesos sociohistóricos del oeste catamarqueño, pp.1744. Sociedad Argentina de Antropología, Buenos Aires.

Ratto, N. 2015. Vivencias, acciones y resultados del quehacer arqueológico en el oeste de Tinogasta (Catamarca, Argentina). Corpus [En línea], Vol 5, No 2 | 2015, Publicado 17/12/15. URL: http:// corpusarchivos. revues.org/1511; DOI: 10.4000/corpusarchivos.1511.

Ratto, N, C. Aranda y L. Luna. 2016. Bioarqueología del Área Valliserrana de Catamarca (siglos VI a XV): nuevos resultados y tendencias. Intersecciones en Antropología 17:157-171.

Ratto, N. y R. Boixadós. 2012. Arqueología y Etnohistoria. La construcción de un problema de investigación (Abaucán, Tinogasta, Catamarca). Revista Memoria Americana 20 (2): 187-220.

Ratto, N., N. Bonomo y A. Osella. 2013 b. Arqueogeofísica en instalaciones del Área del abanico aluvial del río La Troya (departamento Tinogasta, Catamarca). En N. Ratto (comp.), Delineando prácticas de la gente del pasado: Los procesos sociohistóricos del oeste catamarqueño, pp. 337-354. Sociedad Argentina de Antropología, Buenos Aires.

Ratto, N., N. Bonomo y A. Osella. 2019. Arquitectura de la aldea de Palo Blanco (ca. 0-1000 dC), departamento de Tinogasta, Catamarca, Argentina. Latin American Antiquity 30(4): 760-779.

Ratto, N. A. Feely y M. Basile. 2007. Coexistencia de diseños tecno-estilísticos en el período Tardío preincaico: el caso del entierro en urna del Bebé de La Troya (Tinogasta, Catamarca, Argentina). Intersecciones en Antropología 8:69-86.

Ratto, N., V. Lema y M. L. López. 2014. Entierros y ofrendas: Prácticas mortuorias, agrícolas y culinarias en los siglos XIII y XIV en Tinogasta (Catamarca, Argentina). Revista Darwiniana. Nueva Serie 2 (1):125-143.

Ratto, N. M. C. Montero, F. Hongn y B. Valero Garcés. 2013 a. La historia ambiental de las sociedades productivas del oeste tinogasteño (Catamarca), siglos I a XVI. En N. Ratto (comp.), Delineando prácticas de la gente del pasado: Los procesos sociohistóricos del oeste catamarqueño, pp. 45-66. Sociedad Argentina de Antropología, Buenos Aires.

Ratto, N. M. Orgaz y R. Plá. 2002. Producción y 
distribución de bienes cerámicos durante la ocupación Inca entre la región puneña de Chaschuil y el valle de Abaucán (dpto. Tinogasta, Catamarca). Relaciones de la Sociedad Argentina de Antropología XXVII: 271-301.

Ratto, N., M. Orgaz y R. Plá. 2004. La explotación del alfar de La Troya en el tiempo: casualidad o memoria (departamento Tinogasta, Catamarca, Argentina). Chungara. Revista de Antropología Chilena 36 (2): 349361.

Rojas, F. 2013. Rol de la minería y el ferrocarril en el desmonte del oeste riojano y catamarqueño (Argentina) en el período 1851-1942. Población y Sociedad 20 (2):99-123.

Rubiolo, D. (director), 2001. Hoja Geológica 2769-IV. Fiambalá Provincia de Catamarca y La Rioja. Boletín 364. Instituto de Geología y Recursos Minerales. SEGEMAR. Buenos Aires.

Schlanger, S. 1992. Recognizing persistent places in Anasazi settlement systems. En J. Rossignol y L. A. Wandsnider (eds,) Space, time and archaeological landscapes, pp. 91-112. Plenum Press, New York.

Spengler, G. 2017. Arquitectura y asentamiento de las sociedades del Período Tardío del sector centro-norte del valle de Vinchina, La Rioja. Tesis de Doctorado inédita, Universidad de Buenos Aires, Facultad de Filosofía y
Letras. Ms.

Secretaría de Turismo de la Nación (STN). 1998. Argentina: sus museos (Noroeste). Editorial Delfos. Buenos Aires.

Sempé, M. C. 1977. Batungasta: un sitio tardío e incaico en el valle de Abaucán (Dpto. Tinogasta Catamarca). Significación etnohistórica. En Actas y memorias. IV Congreso Nacional de Arqueología Argentina (segunda parte). Revista de Historia Natural de San Rafael: 69-84.

Tineo, A.; J. García; C. Falcón; C. D’ Urso y G. Rodríguez, 1999. Hidrología de la Provincia de Catamarca. XVI ${ }^{\circ}$ Congreso Geológico Argentino. Relatorio Geología del NOA. I: 48-64. Salta.

Togo, J. 1979. Relevamiento arqueológico provincial. Dirección de Antropología de la provincia de Catamarca. Ms.

Uhle, M. 1893. Libreta 0035w266, Número 30, depositada en el Instituto Iberoamericano, Berlín. Ms.

Wachsman, N.; A. B. Callegari, S. E. de Acha y D. M. Soto. 2020. Está que arde. Hornos de cocción cerámica del sitio La Cuestecilla, La Rioja. Análisis de las tecnologías de cocción. Arqueología 26 (1): 13-41

Weiser, W. 1921-1926. Libretas de campo, diarios de viaje y correspondencia de las expediciones al NOA. La Plata, Departamento Científico Arqueología, Museo de La Plata. Ms. 